\title{
ALFABETIZAÇÃO RURAL: PROGRESSOS E DESAFIOS NA REGIÃO DE MANAUS
}

\author{
ALFABETIZAÇÃO RURAL: PROGRESSOS E DESAFIOS NA REGIÃO DE MANAUS
}

\section{Patrícia Maria Medeiros de Andrade}

Universty Sustainable Development-Uds, Asunción, Paraguai. E-mail: patriciamaria.as@hotmail.com

DOI: https://doi.org/10.46550/amormundi.v2i5.115

Recebido em: 28.05.2021

Aceito em: 29.07.2021

\begin{abstract}
Resumo: O presente artigo reflete sobre os progressos e os desafios encontrados na educação do campo na regiâo de Manaus. Se na educação urbana já são altos os desafios imaginamos, ainda mais desafiador é o processo educacional no âmbito rural, em escola com poucos re-cursos pedagógicos e tecnológicos. Por isso, o presente artigo reflete sobre a dificuldade que o professor encontra para lecionar sua matéria e aplicar seus conteúdos da melhor forma possível.
\end{abstract}

Palavras-chave: Desafios. Escolas. Educação. Professores.

Abstract: This article refers to the challenges found in rural education, knowing that in urban educa-tion the challenges we imagine are high in a school with few pedagogical and technological resources. We will focus on the difficulty that the teacher finds to teach his subject and apply its contents in the best way possible. The research will be based on articles, websites and interviews with teachers from rural areas.

Keywords: Challenges. Schools. Education. Teachers.

\section{Introdução}

Z ste estudo fundamenta-se na avaliação teórica das práticas pedagógicas assumidas na educacionais para a populaçáo campestre, através de documentos oficiais e obras que registram historicamente essa evolução, trazem reflexão sobre aspectos que à sombra da rotina nas escolas tornam-se imperceptíveis com o tempo. Porém, estas consideraçôes se fazem sempre necessárias na construção de melhores práticas ao progresso do ensino no Brasil, começando pela comunidade rural na qual a escola estiver inserida.

Orientada por uma perspectiva sócio cultural, a observação empírica acerca das atividades realizadas no âmbito escolar, e até mesmo fora dele, apontam diretrizes a se considera na construção coletiva de conhecimento. Ferramentas e incentivos à realização de uma educação mais palpável, concebidas pelas mentes e mãos de todas as partes interessadas, engajadas com a escola, a comunidade. 
Partindo das observaçóes e análises dirigidas, com resultado percebe-se a influência do discurso pedagógico presente e com forte impacto nas relaçóes, bem como nas atividades cotidianas. Tal interferência apresenta-se nas conclusóes diárias que ao longo do tempo mostram resultados tangíveis, com reflexos que vão de curto a longo prazo na sociedade.

De forma alguma pretendendo privilegiar o trabalho pedagógico como único vetor de avanços sociais, que prevaleça a atenção para o trabalho alfabetizador, visando o domínio de si, independência, maiores chances de progresso individual e coletivo.

\section{Revisão da literatura}

\subsection{Alfabetizaçáo concebida no discurso do docente}

A grande maioria desses educadores e educadoras não estão habituados ao cotidiano do campo, acabando por não se integrar a comunidade escolar afim de conhecê-la, contribuindo no processo de construção de um currículo diferenciado.

Além da escola em si o movimento também é um espaço educativo no qual, como afirma Caldart (2001), há a formação de valores e a educação da sensibilidade; o cultivo da memória e o aprendizado da história; a produção de conhecimentos humanamente significativos; a formação para o trabalho; a formação organizativa; a formação econômica e a formação política.

No que se refere às práticas educativas, Caldart (2004) ainda destaca: as aulas; as oficinas; o trabalho e a produção; a gestão coletiva; as atividades artísticas e lúdicas; a participação em ações do Movimento fora da escola e a sistematização das práticas.

Devemos ressaltar que a pesar do movimento não ter uma pedagogia específica, sua metodologia está baseada na educação popular, por meio de uma concepção criada por Paulo Freire, ou seja, a de que o ser humano é inconcluso e sempre está se formando. Portanto na possibilidade que este tem a capacidade de ser mais que está na obra intitulada Pedagogia do Oprimido de Paulo Freire, compreendendo a natureza humana num processo dinâmico em que o sujeito constitui-se social e historicamente.

Para que verdadeiramente haja uma relação de ensino e aprendizagem é de suma importância a relação de confiança entre educadores e educandos, gestores e comunidade interessada, enfim, entre todos os interessados na escola, para que seja possível estabelecer o que Freire (2005) chamava de uma educação problematizada.

A partir desse pressuposto, os educadores entendem que poderá se construir um conteúdo que realmente faça sentido na vida do educando.

Para tanto, é preciso levar em conta a realidade dos alunos, fazendo a leitura de mundo, investigação que seja conscientizada, fazendo com que cada indivíduo possa se dar conta de sua posição no mundo. Essa perspectiva tem como finalidade possibilitar as pessoas a perceberem-se de sua condição por meio da reflexão crítica em torno das relações homens -homens, homens -mundo, a fim de superá-la (FREIRE, 2001, p. 29-30).

Nesse sentido devemos entender que o campo traz intimamente ligado a si, uma ampla gama de culturas, política, valores, significaçóes, lutas e ideologias e assim consequentemente práticas pedagógicas havendo então uma relação de ensino e aprendizagem, uma experiência 
educativa e a cada experiência um novo aprendizado, que deve fazer parte das políticas públicas implementadas pelo governo e no projeto político pedagógico das escolas do campo.

Faz -se necessário que ressaltemos que o urbano também possui cultura, valores, significaçôes, lutas, ideologias e crenças e por a educação não ser neutra há em cada prática pedagógica uma prática política também, mas na presente pesquisa iremos nos limitar a falar sobre a educação no campo, nunca esquecendo a importância da luta pela qualidade da educação, seja essa no campo ou no meio urbano.

De acordo com Caldart (2004) com seus dirigentes, o MST entra nessa luta como um movimento popular que reivindica a necessidade que seus militantes sentem de verem seus filhos na escola que eles não tiveram e muito mais que estes possam ter uma educação que faça sentido no cotidiano de cada um deles, na vida que eles têm e dentro da luta que eles vivem, fazendo com que estes tenham uma consciência crítica e se formem como sujeitos com uma identidade, identidade de serem sem-terra, ou seja, um sujeito constituído pelas lutas do MST.

Nesse sentido, o MST acaba até por ser uma utopia ao pensar que o mais natural é que aqueles que queiram trabalhar na terra e produzir deveriam tê-la já que esta é um bem natural, mas no sistema capitalista a terra se torna apenas um produto.

O que o movimento faz é entendi do como algo libertador, pois seus militantes que antes eram apenas trabalhadores rurais de integra os de sua terra acabam por se apropriar de uma identidade coletiva de pessoas que querem a mesma coisa, terra para viver, plantar e criar seus filhos, como afirma Caldart (2004, p. 32):

[...] produz uma identidade que primeiro é política, mas que se torna também cultural à medida que recupera raízes, recria relaçôes tradiçôes, cultiva valores, inventa e retrabalha símbolos que demonstram os novos laços sociais e assim faz história.

A educação escolar tem servido, particularmente para manutenção do status quo, dado que esta não tem conseguido atender as necessidades do sujeito do meio rural e algumas dessas escolas só servem como formação de mão-de-obra para o mercado de trabalho capitalista.

Ela continua trabalhando com conceitos desvincula dos da realidade, do meio rural em que as disciplinas estão separadas, compartimentadas, que em muito contribuem para a má qualidade do ensino e para a exclusão, já que poucos conseguem concluir o Ensino Médio e menos ainda o ensino superior.

De acordo com Caldart (2004, p. 90),

Não se pode confundir educação com escola. Escola não é o único espaço de formação humana, mas é um lugar fundamental de educação do povo porque constitui em um tempo e espaço de processos socioculturais que interferem significativamente na formação e no fortalecimento dos sujeitos sociais que dela participam.

A pesquisa também procurou analisar a metodologia da educação e dos educadores do campo, sendo bastante importante para que pudesse refletir sobre uma proposta de educação muito mais ampla do que aquela que formalmente conhecemos e somos levados a internalizá-la como única no de correr de nossas vidas.

Nesse sentido, é interessante analisar a passagem do livro introdutório que apresenta os Parâmetros Curriculares Nacionais do MEC, revelando a forma como é tratada a escola rural: 
[...] as escolas de maior porte, que atendem em média 669,7 alunos e estão localizadas majoritariamente nas áreas urbanas, o que resultado intenso processo de urbanização experimentado pelo país nas últimas décadas [...].

$\mathrm{Na}$ verdade, essas escolas concentram-se na região Nordeste (50\%), não só em função de suas características socioeconômicas, mas também devido à ausência de planejamento no processo de expansão da rede física (BRASIL, 1999, p .18)

Assim percebemos como a escola do campo tem sido ignorada e deixa da fora de grande parte das políticas públicas realizadas nos âmbitos educacionais, por isso que têm resultados pedagógicos insuficientes, altos índices de evasão, grandes números de crianças, jovens e adultos não alfabetizados.

Um dos maiores desafios para a educação escolar em zonas rurais, até pouco tempo atrás sempre foi a educação em salas multisseriadas. Salas de aula com aglomeração de alunos de diferentes idades, séries, níveis bem diversos de conhecimento para se administrar.

Com a disponibilização de novas vagas na rede de ensino municipal, o Grupo de Trabalho e Educação do Campo na Divisão de Ensino Fundamental é responsável pela elaboração, organização e acompanhamento das políticas públicas educacionais voltadas para escolas situadas em área rural na Secretaria Municipal de Educação de Manaus, sempre em parceria com a Divisão Distrital da Zona Rural. Diversas legislaçôes nacionais estaduais e municipais especificas que embasam todos os procedimentos relativos a educação do campo.

Contudo, os esforços que minimizam dificuldades encontradas nas escolas rurais ainda não alcançam satisfatoriamente carências que historicamente são facilmente percebidas nesse meio. Seja pelo natural isolamento logístico e social de comunidades ribeirinhas e vicinais como a E.M. Lago e Silva, há um abandono estrutural que as políticas públicas ainda buscam sanar dia a dia.

Contando com a participação popular, há avanços pontuais, porém, devido a carga de trabalho extenuante na roça, muitos responsáveis por alunos deixam de participar de sua vida escolar. Se não fosse suficiente tentam até mesmo transferir, ainda que inconscientemente, toda a responsabilidade educacional familiar para a escola.

Historicamente a alfabetização rural segue os padróes estabelecidos para os grandes centros urbanos sem levar em consideração as especificidades de cada região do país, de cada micro sociedade disposta ao longo das estradas e rios da região amazônica.

\subsection{Formaçáo de professores}

Nesta breve análise apresentada vemos que os dilemas que caracterizam a política de formação docente, no Brasil de hoje, nos colocam desafios que precisamos enfrentar. Eis os principais:

a) fragmentação e dispersão das iniciativas, justificadas pela chamada "diversificação de modelos de organização da Educação Superior";

b) descontinuidade das políticas educacionais;

c) burocratismo da organização e funcionamento dos cursos no qual o formalismo do cumprimento das normas legais se impóe sobre o domínio dos conhecimentos necessários ao exercício da profissão docente; 
d) separação entre as instituiçóes formativas e o funcionamento das escolas no âmbito dos sistemas de ensino;

e) o paradoxo pedagógico expresso na contraposição entre teoria e prática, entre conteúdo e forma, entre conhecimento disciplinar e saber pedagógico- didático;

f) jornada de trabalho precária e baixos salários (SAVIANI, 2008, p. 119-123).

O enfrentamento desses desafios implica a abertura de novas perspectivas, cujas características se contrapóem simetricamente aos referidos desafios:

a) Contra a fragmentação e dispersão das iniciativas, propomos uma concepção orgânica da formação de professores centrada no padrão universitário e nas faculdades de educação como lócus privilegiado da formação de professores;

b) Contra a descontinuidade das políticas educacionais, defendemos uma política educacional de longo prazo que priorize a formação de professores cultos em cursos de longa duração;

c) Contra o burocratismo da organização e funcionamento dos cursos, propugnamos pela transformação das faculdades de educação em espaços de ensino e pesquisa que possam receber os jovens candidatos ao magistério colocando-os num ambiente de intenso e exigente estímulo intelectual;

d) Contra a separação entre as instituições formativas e o funcionamento das escolas, propomos uma forte articulação entre os cursos de formação e o funcionamento das escolas, considerando dois aspectos: tomar o modo de funcionamento das escolas como ponto de partida da organização do processo formativo e redimensionar os estágios como instrumento que situe a administração dos sistemas de ensino, as escolas de Educação Básica e as faculdades de educação, atuando conjuntamente em regime de colaboração na formação dos novos professores

e) Contra as várias formas de manifestação do paradoxo pedagógico, entendemos que sua solução demanda uma formulação teórica. Esta superaria as oposições excludentes e conseguiria articular teoria e prática, conteúdo e forma, assim como professor e aluno, numa unidade compreensiva desses dois polos que, contrapondo- se entre si, dinamizam e póem em movimento o trabalho pedagógico.

E essa nova formulação teórica foi a tarefa a que se propôs a Pedagogia Histórico-Crítica. Acreditamos que a orientação metodológica posta em movimento por esta pedagogia recupera a unidade da atividade educativa no interior da prática social, articulando seus aspectos teóricos e práticos que se sistematizam na pedagogia concebida ao mesmo tempo como teoria e prática da educação. Superamos, assim, o dilema próprio das duas grandes tendências pedagógicas contemporâneas: a concepção tradicional e a concepçáo renovadora (SAVIANI, 2008).

f) Enfim, em contraste com jornadas de trabalho precárias e com baixos salários é preciso levar em conta que a formação não terá êxito sem medidas correlatas relativas à carreira e às condiçôes de trabalho que valorizem o professor, envolvendo dois aspectos: jornada de trabalho de tempo integral em uma única escola com tempo para aulas, preparação de aulas, orientação de estudos dos alunos, participação na gestão da escola e reunióes de colegiados e atendimento à comunidade; e salários dignos que, valorizando socialmente a profissão docente, atrairão candidatos dispostos a investir tempo e recursos numa formação de longa duração.

Para Clarice Lispector (1984, p. 25), “escrever é difícil. É duro como quebrar rochas”. Os 
desafios enfrentados todos os dias pelos profissionais que atuam na área da educação vão muito além de empecilhos meramente educacionais.

Desde a logística enfrentada pelos discentes e seus familiares para fazer cada dia acontecer na vida escolar do aluno, antes, ainda há os aspectos culturais, socioeconômicos, como limitantes ao contínuo aprendizado acadêmico e pratico nas comunidades.

As populaçôes que vivem às margens de estradas estaduais no Amazonas, vivem em sua realidade com muita determinação para que as esperanças por um futuro melhor seja a realidade das novas geraçóes.

Em seu dia a dia vencem com ressalvas, desafios materiais e intelectuais, intensificados por políticas públicas muitas vezes insuficientes em detrimento à corrupção desmedida, além de dificuldades técnicas e de infraestrutura agravadas por fatores ambientais, sociais, entre outros.

A necessidade de abordar esta temática, nasce da experiência vicária da própria autora. Foram 11 anos de trabalho desenvolvido na educação do município de Manaus - Amazonas. Grande parte de sua história construída paralelamente ao desenvolvimento de uma escola situada às margens da estrada AM 010, no trecho que liga a capital, Manaus, ao município de Rio Preto da Eva.

Foram muitas experiências inclusive extra curriculares, porém totalmente ligadas ao ensino da alfabetização na zona rural, atividades que contribuíram e ainda fomentam o desenvolvimento do ensino fundamental I para as atuais comunidades no entorno da área da Escola Municipal Lago e Silva.

\section{Consideraçóes finais}

Atualmente vivemos tempos em que o nacionalismo volta a ter destaque em suas manifestaçóes populares, demonstradas em atos democráticos e as vezes nem tanto assim. Reflexo de toda a educaçáo implementada até aqui, inclusive, é base para novos trabalhos de aperfeiçoamento de diretrizes, de práticas pedagógicas mais consistentes sob o amparo de políticas públicas educacionais mais inclusivas, na prática.

Em linhas gerais através deste trabalho apresentou-se algumas características do público que frequenta escolas do campo, entre professores, alunos, seus responsáveis e demais membros da comunidade do entorno da Escola Municipal Lago e Silva. Após breve embasamento teórico acerca do tema educação ao longo das décadas no Brasil, falamos de alfabetização e letramento, introduzindo a alfabetização do campo como foco para direcionar nossos esforços de análise ao caso da escola citada.

\section{Referências}

BRASIL. Diretrizes Operacionais para a Educação Básica nas Escolas do Campo. Câmara de Educação Básica do Conselho Nacional de Educação. Edla de Araújo Lira Soares. Brasília Distrito Federal. Parecer No 36/2001. 26p.

CALDART, Roseli Salete. A escola do campo em movimento. Currículo sem fronteiras, v. 3, n. 1, p. 60-81, 2003. 
CALDART, R. S.; MOLINA, M. C. (Orgs.). I Conferência Nacional por um a Educação Básica do Campo. Documentos Finais. Luziânia, GO, 27 a 31 jul. 1998.

FREIRE, P. Conscientização: teoria e prática da libertação: uma introdução ao pensamento de Paulo Freire. São Paulo: Centauro, 2001.

LISPECTOR, Clarice. A hora da estrela. Rio de Janeiro: Nova Fronteira, 1984.

MST. Dossiê MST Escola: Documentos e estudos, 1990 -2001. São Paulo: Expressão Popular, Setor de Educação do MST/Iterra, 2005

SAVIANI, D. História das ide ias pedagógicas no Brasil. Campinas: Autores Associados, 2007. 